\title{
Study on Stress Analysis and Welding Deformation of the Loader Boom
}

\author{
Zhengwen Yuan ${ }^{1,2}, \mathrm{Xi} \mathrm{Lu}{ }^{3}$, Yongneng $\mathrm{Lu}^{1,2}$, Lei $\mathrm{Xu}^{1,2}$ and Shumin $\mathrm{Zhu}^{1,2}$ \\ ${ }^{1}$ Jiangsu Xuzhou Construction Machinery Research Institute, Xuzhou, 221004, China \\ ${ }^{2}$ State Key Laboratory of Intelligent Manufacturing of Advanced Construction Machinery, Xuzhou Construction Machinery Group, \\ Xuzhou, 221004, China \\ ${ }^{3}$ College of Mechanical Engineering, University of Shanghai for Science and Technology, Shanghai, 200093, China
}

\begin{abstract}
This paper takes the 5T loader boom as the research object. Firstly, the static analysis of the boom loader is carried out under the typical working conditions. The weak part of the welding seam is found, and then the welding deformation of the boom is analyzed for the weak welding part. Further, the deformation trends of the welding arm are studied. It is found that the weak part of the welding seam is at the welding arc of the boom plate and the beam. Besides, the deformation of the arm plate is about $30 \mathrm{~mm}$ inward in the welding process due to the welding stress, and the residual stress of the boom. This work can provide theoretical and data support for the processing and deformation correction of the boom.
\end{abstract}

Keywords. loader boom, static analysis, welding deformation, stress.

\section{Introduction}

Wheel loader is a kind of main earthmoving machine used in construction, port, mine, railway, mining and other projects. It can carry out shoveling work on soil, stone and so on. It can also carry out material handling for trucks and other transportation vehicles. A loader completes the work mainly by its working device. It is a space multi-bar mechanism, mainly constructed by bucket, drawbar, swing arm, boom and fuel tank composition. Loader boom is the main load-bearing parts in the working device, mainly made by the plate welding process. During the process, a large weld deformation can occur during the welding of the loader boom plate. This will affect the loader assembly route. It will apply the additional assembly stresses that cause premature fatigue and fracture of the loader boom.

Many scholars have done the research works on the deformation of welded structure. To reduce the welding deformation of the loader tiger and get the optimal scheme of tiger shaped structure welding sequence, the numerical simulation of welding deformation of tiger-shaped structure for rear frame of loader was conducted using thermo elastic-plastic method [1]. As for butt-welding deformation of thick plates in large steel structure, the groove dimensions must be optimized and the rational welding sequence must be adopted [2]. Besides, the three-dimensional numerical simulation of welding process for aluminum alloy thin plate under the conditions of different clamping was also performed by recalls of thermal elastic-plastic FEM technology [3]. The welding deformation of high strength steel with $\mathrm{T}$ joint was studied based on inherent strain theory [4]. The reasons of the deformation is also analyzed aiming at the angle and distort deformation appearing in the course of welding in active arms of loading machine [5].

In this paper, the 5T loader boom is taken as the research object. Firstly, the static analysis of the boom loader is carried out under the typical working conditions. The weak part of the welding seam is found, and then the welding deformation of the boom is analyzed for the weak welding part. Further, the deformation trends of the welding arm are studied. This work can provide theoretical and data support for the processing and deformation correction of the boom.

\section{Static analysis of loader boom}

Figure 1 shows the structure of the loader working device. As shown in this figure, the loader working device consists of four parts: bucket, drawbar, swing arm and boom. When the loader carries out the shoveling operation, the arm cylinder can be stretched and compressed in order to transmit the force to the rod through the rocker arm. The drawbar can drive the bucket to swing around the hinge point of the boom. The boom cylinder can make the whole working device rotate around the front frame. So the materials can be upgraded. As long as the loads connected to the bucket at the three hinge points are calculated, the external workloads on the whole working device can be obtained. 


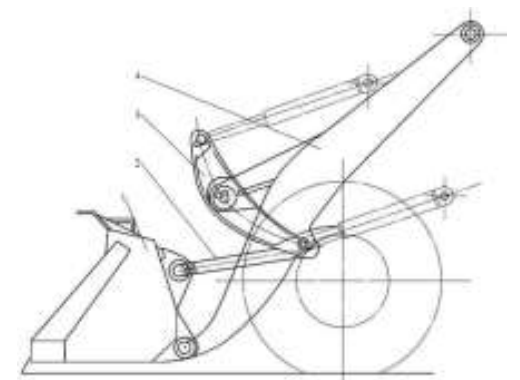

1 - bucket; 2 - drawbar; 3 - swing arm; 4 - boom

Fig. 1. structure of the loader working device.

The three-dimensional model is established by the use of three-dimensional modeling software. Under the precondition of not affecting the basic features and stress of the parts, the non-important features are simplified or neglected, such as smaller roundness, small holes and so on. Figure 2 shows the three-dimensional modeling results of the loader boom.

The three-dimensional solid model of loader boom was directly imported into the finite element software. The material was selected to be Q345. The density of the material Q345 is $7850 \mathrm{~kg} / \mathrm{m} 3$, the Young's modulus was 206000 $\mathrm{GPa}$ and the Poisson's ratio was 0.28 . The initial grid size was set to be $5 \mathrm{~mm}$. then the welding part of loader boom is carried out two grade refinement. The grade division results are shown in Figure 2.

As shown in Figure 2, after two grade refinement for the welding part, the grid of the finite element has been fully refined. Viewing the grid partition by the grid partition command, there are a total of 578,674 nodes and 358,652 units. The mesh quality option was used to check the meshing quality and the results can meet the requirement.

The holes of the boom are in hinged loading conditions under normal operating conditions. So when the constraints are applied, the degree constraint is applied to the hinge hole 3 to restrict the five freedom degrees of the hole, allowing it to rotate about the axis. The freedom degree of the hinge hole 2 is fully constrained. The boundary load is applied to the boom at the positions of the hinge holes 1,4 , and the boom constraint is shown in figure 2 .

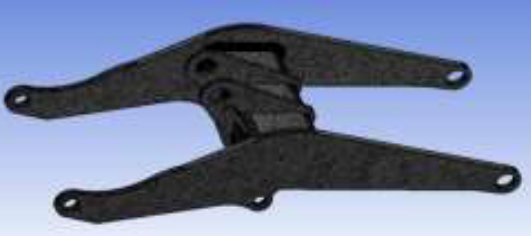

(a) Meshing result

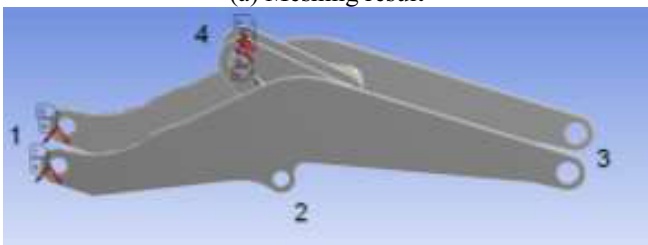

(b) Boundary load and constrain

Fig. 2. Three-dimensional modeling results of the loader boom.

Under the above boundary conditions, the deformation are shown in Figure 3-(a).

According to Figure 3-(a), it can be seen that the total deformation of the boom is in a state of symmetrical distribution. The largest deformation is on the left side, which is about $5.85 \mathrm{~mm}$ and decreasing from left to right. The right side part had less deformation because there applying a hinge constraint at the hole. The deformation at the support arm is less than $1 \mathrm{~mm}$. As shown in figure 3-(b), it is the deformation direction of the boom in working condition. The largest deformation occurs at the left part. The deformation direction is downward.

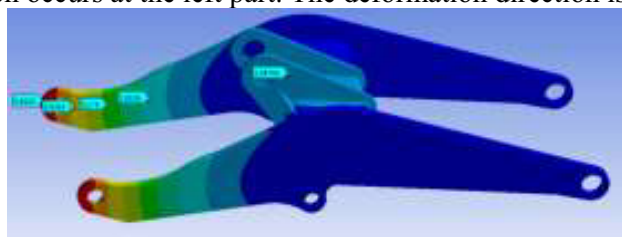

(a)Deformation analysis results of the loader boom 


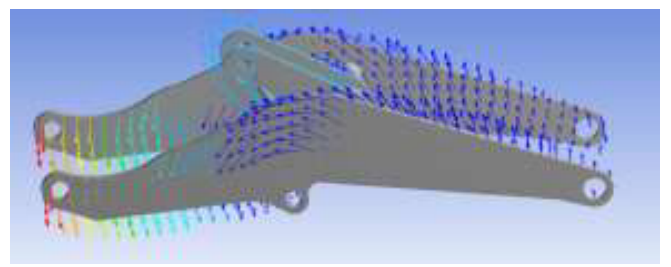

(b)Deformation direction of the boom

Fig. 3. FEM reults.

Based on the finite element simulation, the Von Mises Stress distribution is shown in Figure 4. It can be seen that the stress distribution on both left and right sides are the same. The upper and stress is larger than lower results on each side. The maximum stress of the upper side is about $225 \mathrm{MPa}$, the middle part of the stress is about $20 \mathrm{MPa}$, which is relatively small. The maximum stress of the bottom side is about $183 \mathrm{MPa}$.

For the welded structure, the weld location in the four corners, that is the weld toe part, has relatively larger stress. The largest part occurs in the back corner, which is about $145 \mathrm{MPa}$. Figure 5 shows the Von Mises Stress distribution in the weld part of the boom. As shown in Figure 6, it can be seen that the equivalent stress is larger at the toe of the back corner, and the maximum value is about $145 \mathrm{MPa}$. Figure 6 shows the cutaway view of the weld toe.

From the analysis above, the stress on the weld surface of the four corners is relatively large during the working process of the boom. Although the stress value is smaller than other locations of the boom plate, the heat affected zone exists at the weld part, the microstructure is complex and the welding process is easily led to be micro defects. So the fatigue life of this part is much lower than the base metal. So this position is the weak part of the boom loaded in working conditions. With the introduction of a certain residual stress and welding deformation caused by the assembly of stress, these conditions will certainly increase the risk of fatigue damage. The welding process is simulated as follows.

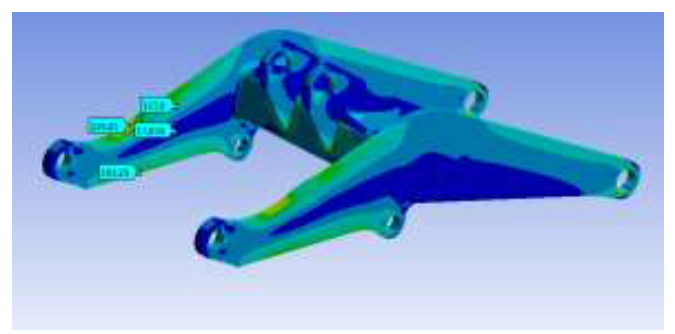

Fig. 4. Von Mises Stress distribution.

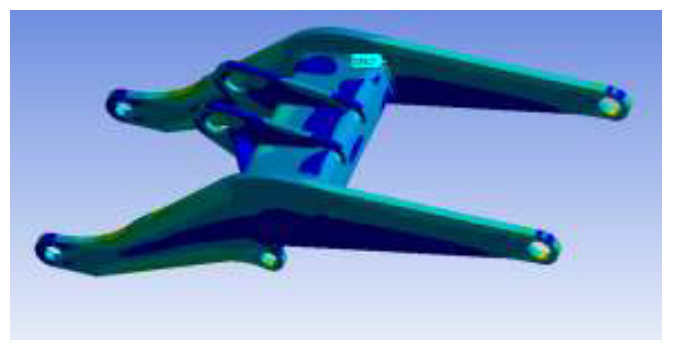

Fig. 5. Von Mises Stress distribution in the weld part of the boom.

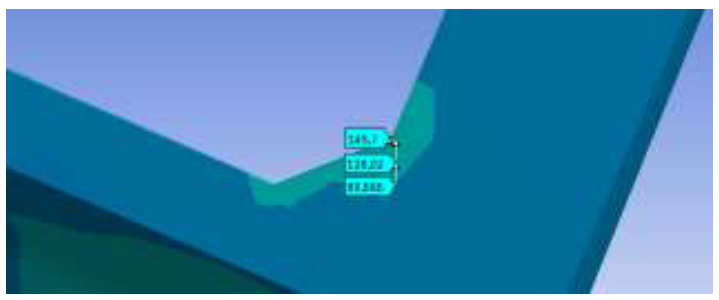

Fig. 6. Cutaway view of the weld toe.

\section{Simulation of the boom welding process}


The physical model of the welding heat source is the prerequisite and condition for the analysis and numerical simulation of the welding heat flow behavior. The commonly used heat source models are the Gaussian surface heat source and the double ellipsoidal heat source model.

The Gaussian surface heat source is suitable for describing the surface welding heat and arc heat distribution on the workpiece surface:

$$
q(r)=q_{m} \exp \left(-K r^{2}\right)
$$

In which is the heat flux at a distance of from the center of the heat source, is the maximum heat flux at the center of the heat source, is the thermal energy concentration factor.

As the total heat on the workpiece surface is equal to the effective power of the welding arc, so

$$
\begin{gathered}
Q=\int_{0}^{\infty} q(r) 2 \pi r d r=q_{m} \int_{0}^{\infty} \exp \left(-K r^{2}\right) 2 \pi r d r \\
=\frac{q_{m} \pi}{-K} \int_{0}^{\infty} \exp \left(-K r^{2}\right) d\left(-K r^{2}\right) \\
q_{m}=\frac{Q K}{\pi}
\end{gathered}
$$

The double ellipsoidal heat source model is widely used in the finite element calculation of the temperature field of various melting welding. Due to the effect of welding speed, the heating area in front of the arc is smaller than that behind the arc. The heated spots are not circular but elliptical. The heat flow distribution in the front of arc can be expression as follows:

$$
q_{f}(x, y)=q_{m f} \exp \left(-A x^{2}-B y^{2}\right)
$$

In which is the Maximum heat flux, $A$ and $B$ is the elliptic distribution parameter.

The heat flow distribution at the back side of the arc can be expressed as follows:

$$
q_{r}(x, y)=q_{m r} \exp \left(-A_{1} x^{2}-B_{1} y^{2}\right)
$$

In which is the Maximum heat flux, and is the elliptic distribution parameter.

So the total heat of the arc front region can be written:

$$
\begin{aligned}
& Q_{f}=2 \int_{0}^{\infty} \int_{0}^{\infty} q_{m f} \exp \left(-A x^{2}-B y^{2}\right) d x d y \\
& =2 q_{m f} \int_{0}^{\infty} \exp \left(-A x^{2}\right) d x \int_{0}^{\infty} \exp \left(-B y^{2}\right) d y
\end{aligned}
$$

By the simulation of the boom welding process, it is found that the boom plate is deformed in the following two cases: the bending of the boom plate inward (see figure 7), the twisting deformation of the boom plate (see figure 8). between These two kinds of deformation, the first deformation is larger, which is about $30 \mathrm{~mm}$. the first deformation can be corrected by press straightening process or pre-deformation of the arm plate the second deformation is relatively small and complex. So it can be ignored. The residual stress can reach 300MPa.

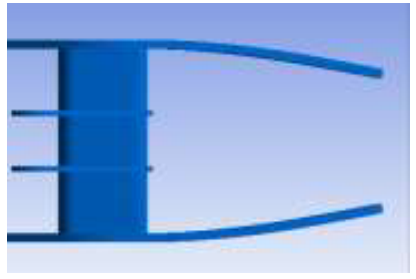

Fig. 7. Bending of the boom plate inward.

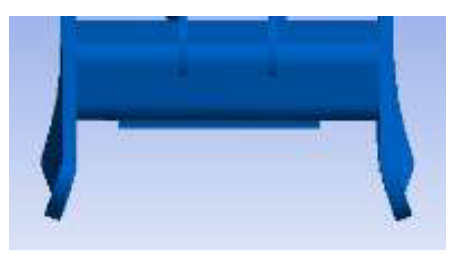

Fig. 8. Twisting deformation of the boom plate. 


\section{Conclusion}

In this paper, the static analysis of the loader boom is carried out under the typical working conditions. It is found that the weak part of the welding seam is at the welding arc of the boom plate and the beam. Then for the weak part, the welding deformation analysis is carried out under the practical process conditions. The deformation and displacement of the boom are also studied. The results show that the deformation of the arm plate is about $30 \mathrm{~mm}$ inward in the welding process due to the welding stress, and the residual stress of the boom. The residual stress can reach $300 \mathrm{MPa}$. This study can provide theoretical and data support for the processing and deformation correction of the boom.

\section{Acknowledgment}

This work is supported by the National Natural Science Foundation of China (51175346), Shanghai automotive industry science and technology development foundation (1623), and the Key Scientific and Technological Projects of Shanghai (14521100500).

\section{References}

1. G.T. zhou, H. zhang, Z.W. Cheng, Numerical simulation analysis for welding sequence optimization of hinge structure of loader, Material science \& technology, 24(3):62-67. (2016)

2. Z.B. Zeng, Z.Q. Shi, Y.J. Shi, Experimental Research on Butt-Welding Deformation of Thick Plates in Large Steel Structure, CHINA RAII WAY SCIENCE, 30(3):33-39. (2009)

3. J.Q.Zhang, H.Y. Zhao, Effects of Clamps on Welding Distortion in Thin Aluminum Alloy Plate, RARE METAL MATERIALS AND ENGINEERING, 38(z3):165-169. (2009)

4. D.Y. Huang, Numerical Modeling on Welding Deformation and Inherent Strain of High-strength Steel with Tjoint, Hot Working Technology, 2013, 42(11):218-221,22. (2013)

5. X.G. Xu, Y.S. Bi, X. Wang, Control of Welding Deformation in the Active Arms Of Loading Machine, JOURNAL OF CHONGQING UNIVERSITY(NATURAL SCIENCE EDITION), 27(3):13-15. (2004) 